\title{
Sleep Apnoea in Patients With Nocturnal Hypertension - a Multicenter Study in the Czech Republic
}

\author{
M. HOBZOVA ${ }^{1}$, K. SONKA ${ }^{2}$, M. PRETL ${ }^{3}$, J. VACLAVIK ${ }^{4}$, E. KRIEGOVA ${ }^{5}$, \\ M. RADVANSKY ${ }^{6}$, J. ZAPLETALOVA ${ }^{7}$, M. PLACKOVA ${ }^{8}$, V. KOLEK ${ }^{1}$
}

${ }^{1}$ Department of Respiratory Medicine, Faculty of Medicine and Dentistry, Palacky University Olomouc and University Hospital Olomouc, Czech Republic, ${ }^{2}$ Department of Neurology, First Faculty of Medicine, Charles University and General University Hospital, Prague, Czech Republic, ${ }^{3}$ Neurology and Sleep Laboratory, INSPAMED, Prague, Czech Republic, ${ }^{4}$ Department of Internal Medicine I - Cardiology, Faculty of Medicine and Dentistry, Palacky University Olomouc, Czech Republic, ${ }^{5}$ Department of Immunology, Faculty of Medicine and Dentistry, Palacky University Olomouc, Czech Republic, ${ }^{6}$ Department of Computer Science, Faculty of Electrical Engineering and Computer Science, VSB-Technical University of Ostrava, Czech Republic, ${ }^{7}$ Department of Medical Biophysics, Faculty of Medicine and Dentistry, Palacky University Olomouc, Czech Republic, ${ }^{8}$ Department of Respiratory Medicine, University Hospital Ostrava, Czech Republic

Received December 12, 2016

Accepted September 21, 2017

On-line January 5, 2018

\section{Summary}

Sleep apnoea (SA) is common in patients with hypertension. Nowadays, limited data on the prevalence of SA in nocturnal hypertension $(\mathrm{NH})$ exist. Therefore, we studied the occurrence of $\mathrm{SA}$ in Czech patients and its association with 24-h ambulatory blood pressure monitoring (ABPM), breathing disturbances in sleep, anthropometric data, Mallampati score and Epworth sleepiness scale (ESS) using the Apnea Link device. Undiagnosed SA was found in $72.9 \%$ patients $(29.3 \%$ mild, $26.6 \%$ moderate, $17.0 \%$ severe) of 188 patients with $\mathrm{NH}$ measured by ABPM. The median of the apnoea-hypopnoea index (AHI) was 12.0 (25th-75th percentile 5.0-23.8). Moderate/severe SA $(\mathrm{AHI} \geq 15)$ was associated with BMI, waist circumference, mean night saturation $\left(\mathrm{SpO}_{2}\right)$, t90, oxygen desaturation index (ODI), ESS (daytime BP only) ( $p \leq 0.032)$, but not ABPM parameters and Mallampati score $(p>0.09)$. A likelihood of moderate/severe SA was enhanced by ODI $>14.5$ events $/ \mathrm{h}$ (odds ratio=57.49, $95 \% \mathrm{CI}=22.79-145.01)$, t90>6.5\% (8.07, 4.09-15.92), mean night $\mathrm{SpO}_{2}<93.5 \%(3.55,1.92-6.59), \mathrm{BMI}>29.05 \mathrm{~kg} / \mathrm{m}^{2}(6.22$, $3.10-12.49)$, circum waist $>105.5 \mathrm{~cm}(3.73,1.57-8.83)$, but not by any ABPM parameter. In conclusion, a high incidence of SA (72.9\%) was observed in Czech patients with $\mathrm{NH}$. SA severity was associated with body characteristics and oxygenation parameters, but not with ABMP parameters and Mallampati score.

\section{Key words}

Sleep apnoea - Nocturnal hypertension - Ambulatory blood pressure monitoring - Mallampati score • Epworth sleepiness scale • BMI

\section{Corresponding author}

M. Hobzová, Department of Respiratory Medicine, Faculty of Medicine and Dentistry, Palacky University Olomouc and University Hospital Olomouc, I. P. Pavlova 6, 77920 Olomouc, Czech Republic. E-mail: milada.hobzova@seznam.cz

\section{Introduction}

Obstructive sleep apnoea (OSA) is one of the most common sleep-disordered breathing (SDB), characterized by repeated obstruction of the upper airways during sleep, leading to hypopnoea (reduced air flow to $20-70 \%$ of previous steady breathing) or apnoea (complete cessation of airflow and decrease in flow through the respiratory tract to $<20 \%$ of previous stable breathing), lasting at least $10 \mathrm{~s}$ (Parati et al. 2012, 
Qaseem et al. 2014). These events may occur more than five times per hour of sleep accompanied by awakening and/or arousal reactions. The incidence of OSA, according to major studies is between 3-7 \% in adult men and $2-5 \%$ in adult women (Lindberg 2010). The prevalence of OSA is higher in patients with hypertension (30-83\%), heart failure (12-53\%), ischemic heart disease (30-58\%) and stroke (43-91\%) (Bradley and Floras 2009). OSA is also found in 64-83\% of patients with resistant hypertension (Logan et al. 2001), of whom more than $55 \%$ have moderate to severe forms (Gonçalves et al. 2007, Pedrosa et al. 2011).

Patients with OSA exhibit a high prevalence of nocturnal blood pressure (BP) with non-dipping or rising pattern, which is related to clinical and subclinical organ damage to heart and brain (Torres et al. 2015). The pathogenesis of OSA is multifactorial, involving airway obstructions resulting in hypoxia and hypercapnia increasing sympathetic neural tone, which in turn causes vasoconstriction and marked increases in BP (Wolf et al. 2010). Besides this, intermittent hypoxia associated with hyperaldosteronism, endothelial dysfunction, nocturnal fluid redistribution, sleep inefficiency, increased sympathetic tone, oxidative stress and inflammation are involved in the pathogenesis (Khan et al. 2013, Phillips et al. 2013, Konecny et al. 2014, Fernandez-Mendoza et al. 2012). However, the relationship of OSA to nocturnal hypertension is still unclear. Moreover, there is no data on OSA in Czech patients with nocturnal hypertension and on the incidence of sleep apnoea (SA), or other breathing disorders linked to sleep.

The aim of this multicenter study was: i) to assess the prevalence of undiagnosed SA in patients with nocturnal hypertension, assessed by 24-h ambulatory BP monitoring (ABPM) and determine the relationship of ABPM to the apnoea-hypopnoea index (AHI), other variables of oxygenation during sleep, and anthropometric characteristics; ii) to determine whether the Mallampati score, and Epworth sleepiness scale (ESS) questionnaire correlate with hypertension; iii) to determine whether, for those with nocturnal hypertension and daytime normotensive BP there is a higher incidence of SA than those with hypertension, day and night.

\section{Methods}

\section{Patients}

Study cohort consists of consecutive patients with nocturnal hypertension, who were referred by a cardiologist or an internist for examination at a sleep center (Fig. 1). Nocturnal hypertension was defined as nighttime systolic and/or diastolic BP means $\geq 120 / 70 \mathrm{~mm} \mathrm{Hg}$ (Parati et al. 2014, Mancia et al. 2013). Four accredited sleep centers in the Czech Republic took part in this study. Enrolled patients were those treated for hypertension with no night drop in pressure (non-dippers), patients with isolated nocturnal hypertension and those with persistent high BP day and night despite treatment. Exclusion criteria were age below 18 years, sleep apnoea and other sleep disorders in the history, neuromuscular disease, stroke, severe pulmonary obstruction associated with bronchial asthma and chronic obstructive pulmonary disease, other secondary hypertension (endocrine disorders, renal artery stenosis, renal parenchymal disease, intracranial tumors), pulmonary fibrosis, clinical signs of heart failure, treatment with benzodiazepines and myorelaxants or lack of interest in participation.

All patients signed an informed consent, and the study was approved by local ethics committees.

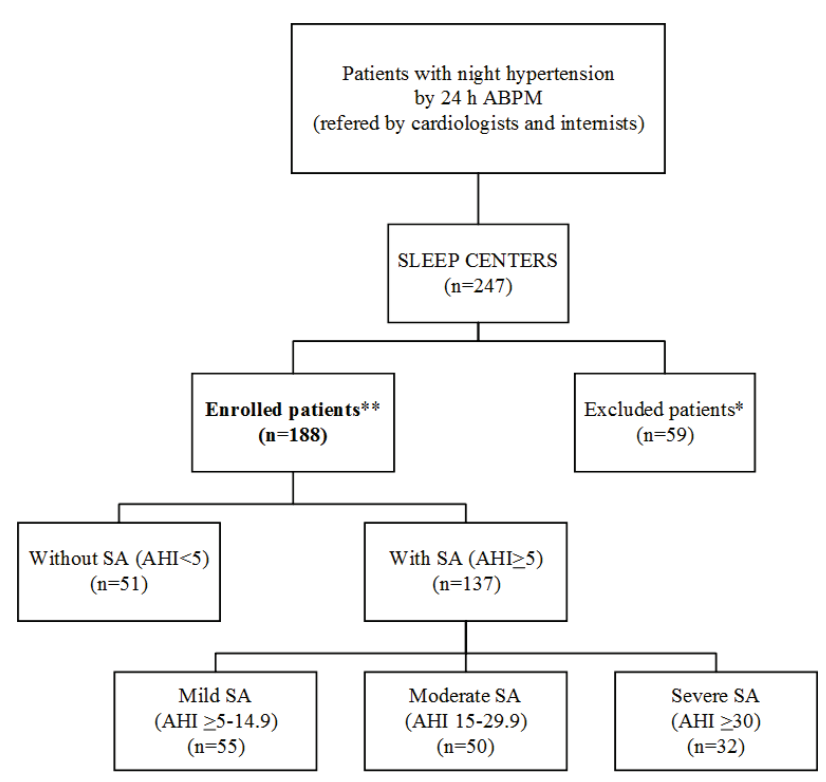

Fig. 1. Flow chart of patients who met inclusion/exclusion criteria for this study. $* *$ Inclusion criteria: patients with night hypertension: i) non-dippers - those treated for hypertension with no night drop in pressure, ii) patients with isolated nocturnal hypertension and iii) those with persistent high BP day and night despite treatment. * Exclusion criteria: age below 18 years, sleep apnoea and other sleep disorders in the history, neuromuscular disease, stroke, severe pulmonary obstruction (bronchial asthma and chronic obstructive pulmonary disease), pulmonary fibrosis, other secondary hypertension (endocrine disorders, renal artery stenosis, renal parenchymal disease, intracranial tumors), clinical signs of heart failure, treatment with benzodiazepines and myorelaxans or lack of interest in participation. 


\section{Demographic and clinical data}

Following demographic and medical history data were recorded in all enrolled patients: age, gender, snoring, apnoea occurrence, other concomitant diseases, especially coronary heart disease (CHD) and myocardial infarction, and hypertensive medication. We established the proportion of patients treated for hypertension. The percentage of patients with SA (mild, moderate, severe) and without SA was then determined. The investigation involved completing ESS questionnaire which captures daytime somnolence in eight different everyday situations for the last week. Excessive daytime sleepiness is considered a score of 10 or higher (Johns 1991).

\section{Anthropometry}

We measured body characteristics height, weight, body mass index (BMI), neck, waist, and hip circumference, the Mallampati class - classification of visibility of the oropharynx for intubation (Mallampati 1983). The Mallampati score is assessed by asking the patient (in a sitting posture) to open his/her mouth and protrude the tongue as far as possible. The anatomy of the oral cavity is visualized; specifically, whether the base of the uvula, faucial pillars (the arches in front of and behind the tonsils) and soft palate are visible. Following Mallampati classes were evaluated: class I (soft palate, uvula, fauces, pillars visible), class II (soft palate, uvula, fauces visible), class III (soft palate, base of uvula visible), and class IV (only hard palate visible).

\section{Sleep respiration studies}

The night screening for sleep apnoea was done in all enrolled patients on an outpatient basis using the Apnea Link device (ResMed Inc, Bella Vista, Australia). The Apnea Link device is a simple, easy-to-use device, and is highly sensitive and specific in calculating the AHI compared with the AHI from full polysomnography (Erman et al. 2007). Apnea Link device monitors the apnoea and hypopnoea from the respiratory flow (nasal cannula), snoring, oximetry and pulse rate from the sensor of the pulse oximeter, and it assesses CheyneStokes respiration probability from the flow. The record lasted $6-8 \mathrm{~h}$. A shorter recording than $6 \mathrm{~h}$ or non-valid records were repeated the following night. The record was visually evaluated for the following data: AHI (apnoea-hypopnoea index - the number of apnoeas and hypopnoeas per hour of registration), ODI (oxygen desaturation index - the number of drops in desaturation by $4 \%$ per hour of registration), average night saturation in \% (mean $\left.\mathrm{SpO}_{2}\right)$ and 90 (time in saturation below $90 \%$ oxygen saturation $\left(\mathrm{SaO}_{2}\right)$, expressed in \%) and the presence or absence of Cheyne-Stokes respiration (proportion of probable $0.5 \%$ Cheyne-Stokes epochs). SA was assessed according to the AHI as mild for $\mathrm{AHI}=5-14.9$, moderate for $\mathrm{AHI}=15-29.9$ and $\mathrm{AHI} \geq 30$ as severe (Flemons et al. 1999).

\section{Ambulatory blood pressure monitoring}

Measurement of 24-h ABPM started each morning at 07-08 a.m. The average 24-h BP was calculated along with average daytime and nighttime BP (systolic and diastolic) from which the percentage of non-dippers (a BP drop $<10 \%$, both systolic and diastolic) was estimated. Normal average BP values on ABPM were daytime $<135 / 85 \mathrm{~mm} \mathrm{Hg}$, night time $<120 / 70 \mathrm{~mm} \mathrm{Hg}$ and average over $24-\mathrm{h}<130 / 80 \mathrm{~mm} \mathrm{Hg}$ (Mancia et al. 2013). The incidence of SA was compared in patients with nocturnal hypertension and daytime normotension and those with day and night hypertension.

\section{Statistical methods}

The statistical analyses (nonparametric MannWhitney U-test, Kruskal-Wallis test, Receiver-Operator Characteristic (ROC) curves, chi-squared test) were performed using the software IBM SPSS Statistics 22 (US) and R statistical software (https://www.r-project.org/). The normality of the data was tested using the Shapiro-Wilk test. The data are shown as medians (25th-75th percentile). A logistic regression model was used to estimate Odds Ratio with a $95 \%$ confidence interval (CI) for categorical variables. Spearman correlation coefficient was used for assessment of correlations between studied parameters. A $p$-value $<0.05$ was considered significant.

\section{Results}

\section{Patient characteristics}

We examined 188 patients (male/female 123/65; median age 59.0 years) with nocturnal hypertension. Descriptive characteristics of patients and ABPM data are shown in Table 1. On ABPM, $89 \%$ were non-dippers for systolic BP and $71 \%$ non-dippers for diastolic BP. $97.6 \%$ patients were on medication for hypertension. From ABPM, only $27.1 \%$ of patients had systolic BP within the norm in the daytime, and only $3.2 \%$ at the night interval. Diastolic BP was more often within the norm (daytime $59.0 \%$, nighttime $18.1 \%$ ). 
Table 1. Demographic and clinical characteristics of enrolled subjects including the ambulatory BP monitoring data and subjective evaluation of daytime sleepiness and night registrated breathing data. Data are shown as median, 25th-75th percentiles in parenthesis.

\begin{tabular}{|c|c|c|c|}
\hline & $\begin{array}{l}\text { Whole sample set } \\
\qquad n=188\end{array}$ & $\begin{array}{c}\text { Male } \\
\mathrm{n}=123\end{array}$ & $\begin{array}{c}\text { Female } \\
n=65\end{array}$ \\
\hline Age (years) & $\begin{array}{c}59.0 \\
(53.0-65.0)\end{array}$ & $\begin{array}{c}58.0 \\
(50.0-64.0)\end{array}$ & $\begin{array}{c}62.0 \\
(58.0-67.0)\end{array}$ \\
\hline Medical history of snoring (\%) & $71.5 \%$ & $76.2 \%$ & $62.5 \%$ \\
\hline Medical history of apnoea (\%) & $41.8 \%$ & $46.3 \%$ & $33.3 \%$ \\
\hline ESS & $\begin{array}{c}6.0 \\
(3.0-9.0)\end{array}$ & $\begin{array}{c}6.0 \\
(3.0-9.0)\end{array}$ & $\begin{array}{c}5.0 \\
(2.0-9.0)\end{array}$ \\
\hline \multicolumn{4}{|l|}{ Anthropometry } \\
\hline$B M I\left(\mathrm{~kg} / \mathrm{m}^{2}\right)$ & $\begin{array}{c}30.9 \\
(27.4-35.1)\end{array}$ & $\begin{array}{c}30.5 \\
(27.3-34.5)\end{array}$ & $\begin{array}{c}31.2 \\
(28.0-36.0)\end{array}$ \\
\hline Neck circumference (cm) & $\begin{array}{c}42.0 \\
(39.0-44.0)\end{array}$ & $\begin{array}{c}43.0 \\
(41.0-45.0)\end{array}$ & $\begin{array}{c}39.0 \\
(36.5-40.0)\end{array}$ \\
\hline Waist circumference $(\mathrm{cm})$ & $\begin{array}{c}108.0 \\
(98.0-115.0)\end{array}$ & $\begin{array}{c}109.0 \\
(100.0-117.5)\end{array}$ & $\begin{array}{c}103.0 \\
(95.0-114.0)\end{array}$ \\
\hline Hip circumference $(\mathrm{cm})$ & $\begin{array}{c}108.0 \\
(103.8-115.2)\end{array}$ & $\begin{array}{c}107.0 \\
(102.5-114.0)\end{array}$ & $\begin{array}{c}110.0 \\
(105.0-117.0)\end{array}$ \\
\hline \multicolumn{4}{|l|}{$A B P M$} \\
\hline 24-h systolic (mm Hg) & $\begin{array}{c}139.0 \\
(133.0-149.0)\end{array}$ & $\begin{array}{c}139.9 \\
(134.0-151.0)\end{array}$ & $\begin{array}{c}138.0 \\
(133.0-143.5)\end{array}$ \\
\hline 24-h diastolic ( $\mathrm{mm} \mathrm{Hg}$ ) & $\begin{array}{c}80.0 \\
(76.0-87.0)\end{array}$ & $\begin{array}{c}81.0 \\
(77.0-89.0)\end{array}$ & $\begin{array}{c}78.0 \\
(69.0-83.0)\end{array}$ \\
\hline Daytime systolic ( $\mathrm{mm} \mathrm{Hg}$ ) & $\begin{array}{c}140.0 \\
(134.0-149.0)\end{array}$ & $\begin{array}{c}142.0 \\
(134.0-152.0)\end{array}$ & $\begin{array}{c}137.0 \\
(131.8-145.0)\end{array}$ \\
\hline Daytime diastolic ( $\mathrm{mm} \mathrm{Hg}$ ) & $\begin{array}{c}83.0 \\
(76.0-90.0)\end{array}$ & $\begin{array}{c}84.0 \\
(78.0-92.0)\end{array}$ & $\begin{array}{c}79.0 \\
(72.0-85.0)\end{array}$ \\
\hline Nighttime systolic (mm Hg) & $\begin{array}{c}139.0 \\
(131.0-149.0)\end{array}$ & $\begin{array}{c}139.0 \\
(130.0-150.0)\end{array}$ & $\begin{array}{c}140.0 \\
(131.0-148.0)\end{array}$ \\
\hline Nighttime diastolic (mm Hg) & $\begin{array}{c}78.0 \\
(73.0-85.0)\end{array}$ & $\begin{array}{c}80.0 \\
(75.0-87.0)\end{array}$ & $\begin{array}{c}75.0 \\
(66.2-85.0)\end{array}$ \\
\hline \multicolumn{4}{|l|}{ Respiration parameters } \\
\hline AHI (events/h) & $\begin{array}{c}12.0 \\
(5.0-23.8)\end{array}$ & $\begin{array}{c}14.0 \\
(6.0-28.5)\end{array}$ & $\begin{array}{c}10.0 \\
(5.0-21.0)\end{array}$ \\
\hline ODI (events/h) & $\begin{array}{c}10.5 \\
(5.0-22.8)\end{array}$ & $\begin{array}{c}13.0 \\
(6.0-26.0)\end{array}$ & $\begin{array}{c}8.0 \\
(5.0-16.0)\end{array}$ \\
\hline Mean $\mathrm{SpO}_{2}(\%)$ & $\begin{array}{c}93.0 \\
(92.0-95.0)\end{array}$ & $\begin{array}{c}93.0 \\
(92.0-95.0)\end{array}$ & $\begin{array}{c}93.0 \\
(92.0-95.0)\end{array}$ \\
\hline$t 90(\%)$ & $\begin{array}{c}8.0 \\
(1.0-25.8)\end{array}$ & $\begin{array}{c}9.0 \\
(1.0-25.0)\end{array}$ & $\begin{array}{c}6.0 \\
(2.0-27.0)\end{array}$ \\
\hline
\end{tabular}

ABPM - 24-h ambulatory BP monitoring, ESS - Epworth sleepiness scale, AHI - apnoea-hypopnoea index, ODI - oxygen desaturation index, Mean $\mathrm{SpO}_{2}$ - mean night saturation (\%), t90 \% - time in saturation below $90 \% \mathrm{SaO}_{2}$.

Of enrolled patients, $27.1 \%$ had no SA $(\mathrm{AHI}<5)$ and in $72.9 \%$ patients $\mathrm{SA}(\mathrm{AHI} \geq 5)$ was detected. Of those with SA, $29.3 \%$ had mild SA, $26.6 \%$ moderate SA and $17.0 \%$ severe SA.

Results for ESS and night registrated breathing are presented in Table 1. Cheyne-Stokes breathing 
probability was demonstrated in $4.8 \%$ patients $(4.3 \%$ of men, $0.5 \%$ women). Numbers of apnoea with CheyneStokes respiration are included in the AHI.

\section{Mallampati score}

In the whole sample set, the Mallampati class I was observed in 32 patients $(17.0 \%)$, class II in 68 patients $(36.2 \%)$, class III in 62 patients $(33.0 \%)$, and class IV in 26 patients (13.8\%).

Comparison of patient data in subgroups according to the AHI

When comparing patients without $\mathrm{SA}(\mathrm{AHI}<5)$ with those with $\mathrm{SA}(\mathrm{AHI} \geq 5)$, we observed higher occurence of snorring $(p=0.007)$ and apnoea $(p<0.001)$ in the medical history, $B M I>30(p=0.009)$, medical history of coronary artery disease $(\mathrm{p}=0.015)$, Mallampati class IV $(p<0.001)$ in patients with SA. Patients without SA and with SA did not differ in the pathological $E S S \geq 10$ $(p=0.222)$, drug treatment for hypertension $(p=0.580)$, and history of myocardial infarction $(\mathrm{p}=0.236)$.

Comparison of body characteristics and oxygenation parameters in patients without $\mathrm{SA}(\mathrm{AHI}<5)$ with SA subgroups according to the AHI (mild, moderate and severe SA) is shown in Figure 2. The Kruskal-Wallis test revealed the differences in weight $(\mathrm{p}<0.001)$, BMI $(p=0.003)$, neck circumference $(p<0.001)$, waist circumference $(p<0.001)$, hip circumference $(p<0.001)$ as well as in the parameters: night saturation $\mathrm{SpO}_{2}$ $(p<0.001)$, higher t90 $(p<0.001)$ and ODI $(p<0.001)$ between studied subgroups.

Comparison of ABPM parameters between patient's subgroups with no SA and mild SA (AHI=5-14.9) and moderate and severe $\mathrm{AHI}(\mathrm{AHI} \geq 15)$ is shown in Figure 3. Only patients with $\mathrm{AHI} \geq 15$ were treated with continuous positive airway pressure (CPAP). No differences were observed between subgroups in 24-h systolic $(\mathrm{p}=0.906), 24-\mathrm{h}$ diastolic $(\mathrm{p}=0.959)$, daytime systolic $(p=0.923)$, daytime diastolic $(p=0.893)$, nighttime systolic $(p=0.397)$, nighttime diastolic BP $(p=0.234)$.

When comparing patients according to the severity of SA, we observed higher occurrence of BMI $>30(p<0.001)$, waist circumference $(p=0.001)$, and trend for higher neck circumference $(p=0.066)$ in moderate/severe SA comparing with mild SA. We also detected higher occurrence of lower mean night saturation $\mathrm{SpO}_{2}(\mathrm{p}<0.001)$, higher t90 $(\mathrm{p}<0.001)$ and higher ODI $(p=0.032)$ in moderate/severe cases comparing to mild SA cases. Regarding ABPM parameters, we did not observe any significant association with the studied parameters: 24-h systolic $(\mathrm{p}=0.095), 24-\mathrm{h}$ diastolic $(\mathrm{p}=0.816)$, daytime systolic $(\mathrm{p}=0.996)$, daytime diastolic $(\mathrm{p}=0.451)$, nighttime systolic $(p=0.272)$, nighttime diastolic $(p=0.895)$. Combination of BMI $>30$ with high $\mathrm{t} 90$ or high ODI further increase the significance $(\mathrm{p}<0.001)$ between studied subgroups.

In order to establish the sensitivity and specificity of investigated parameters as well as to determine the threshold for the best separation of patients without SA and mild SA and those with moderate and severe SA, we constructed the ROC curves. The highest sensitivity $81.5 \%$ and specificity $93.4 \%$ (for threshold 14.5, area under curve (AUC) 0.921) was observed for ODI, followed by $\mathrm{t} 90$ (threshold 6.5 , sensitivity $82.5 \%$, specificity 65.1\%, AUC 0.790), mean night $\mathrm{SpO}_{2}$ (93.5, sensitivity $71.6 \%$, specificity $52.5 \%$, AUC 0.719 ), BMI $\left(29.05 \mathrm{~kg} / \mathrm{m}^{2}\right.$, sensitivity $84.0 \%$, specificity $55.1 \%$, AUC 0.698) and age (63.5 years, sensitivity $43.2 \%$, specificity $75.7 \%$, AUC 0.594) (Fig. 4). For neck circumference the ROC revealed $(40.5 \mathrm{~cm}$, sensitivity $74.1 \%$, specificity $52.3 \%$, AUC 0.668), for waist circumference $(105.5 \mathrm{~cm}$, sensitivity $75.3 \%$, specificity $62.6 \%$, AUC 0.737) and hip circumference $(111.5 \mathrm{~cm}$, sensitivity $58.0 \%$, specificity $79.4 \%$, AUC 0.718 ) for compared groups. The ROC curve analysis showed that the AUC of AMBP 24-h systolic, 24-h diastolic, daytime systolic, daytime diastolic, nighttime systolic, nighttime diastolic was $0.50,0.51,0.49,0.51,0.52,0.54$, respectively.

\section{Correlation analysis}

Correlations of the ABPM parameters with the results of other nocturnal breathing registration (ODI, mean $\mathrm{SpO}_{2}$, t90), anthropometric parameters, ESS and Mallampati score in subgroups of patients divided according to the $\mathrm{AHI}(\mathrm{AHI}=0-14.9$ vs. $\mathrm{AHI} \geq 15)$ are shown in Figure 5. The analysis showed no correlation of ABPM parameters with severity of SA, nor with AHI and other studied parameters (Fig. 5). In both studied subgroups according to the AHI, a strong correlation between respiratory parameters (ODI, average night saturation and t90) as well as body characteristics (height, weight, BMI, neck, waist and hip circumference was observed (Fig. 5). 


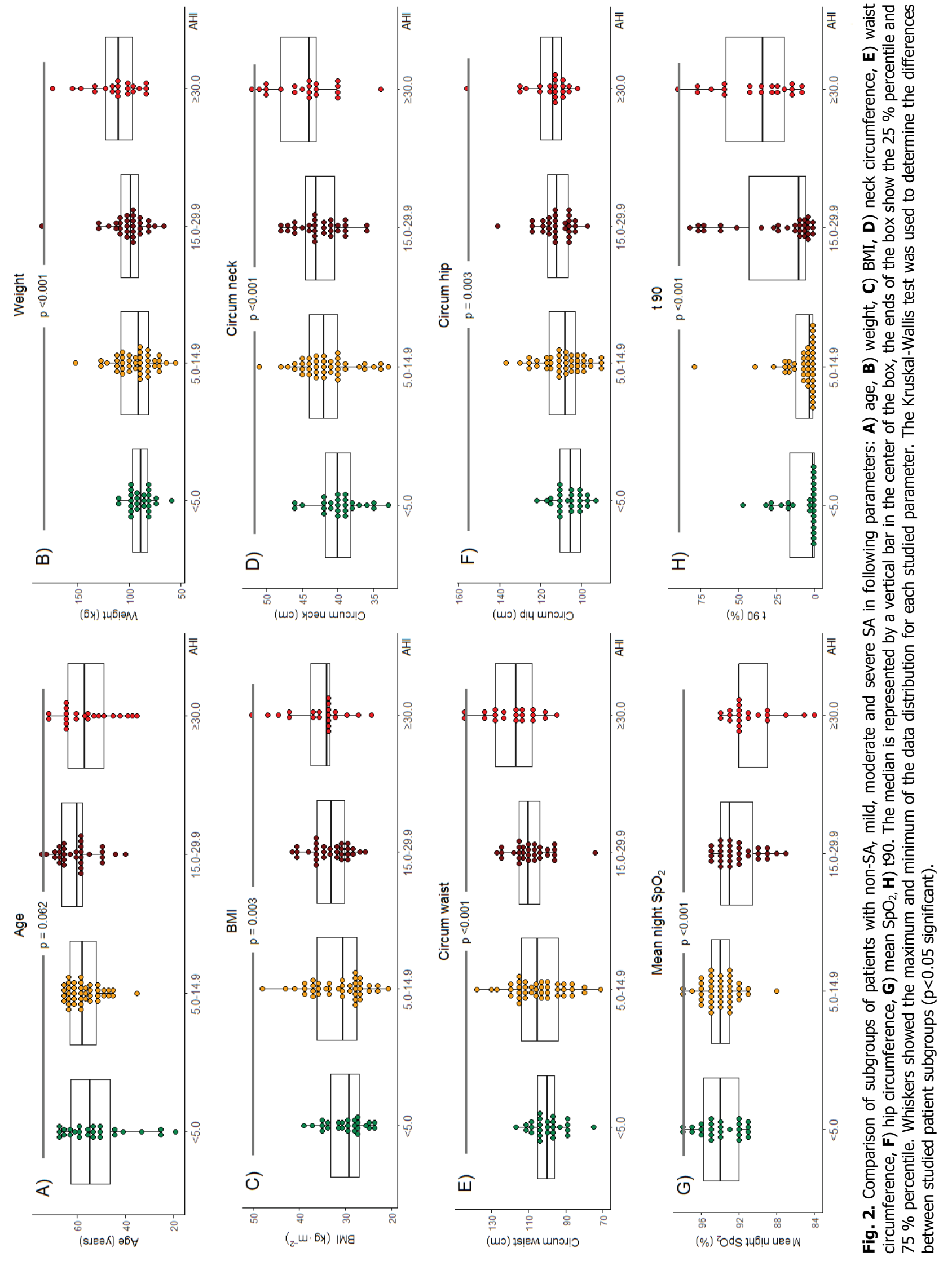




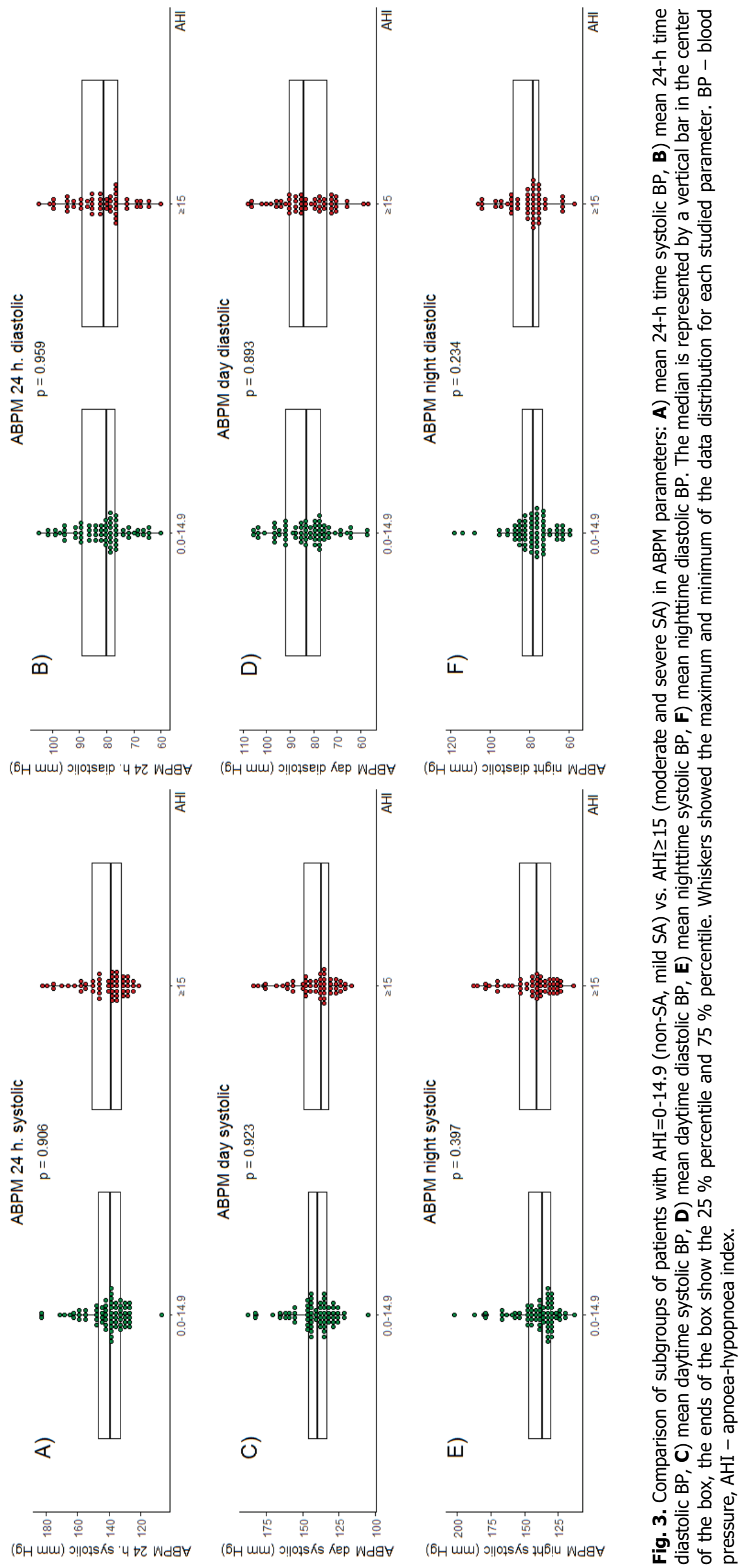


A)

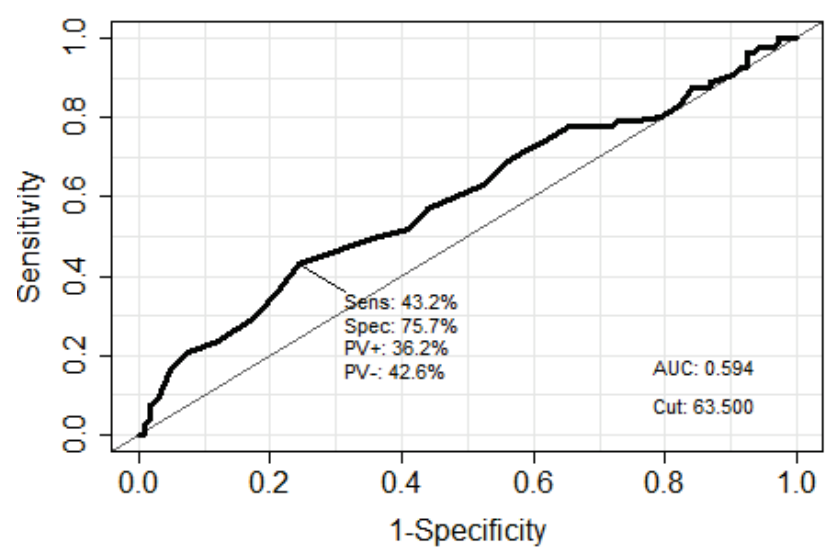

C) ROC curve: Mean night $\mathrm{SpO}_{2}(\%)$

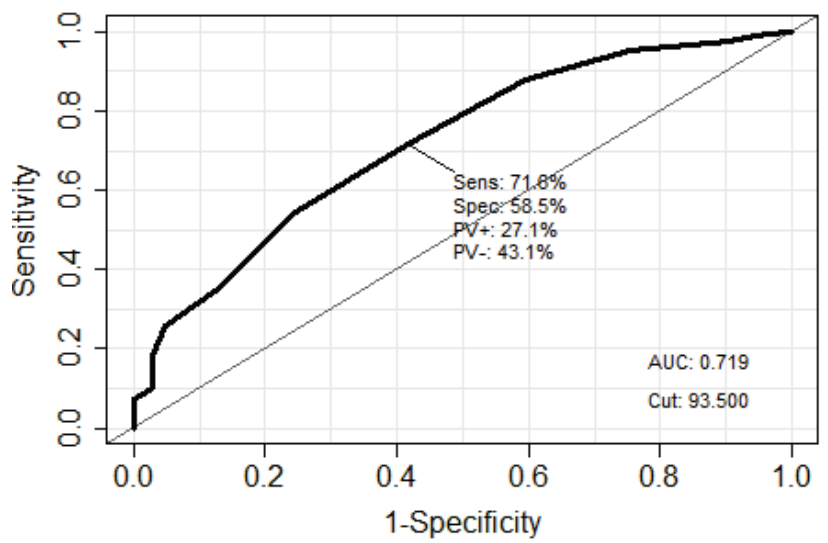

E)

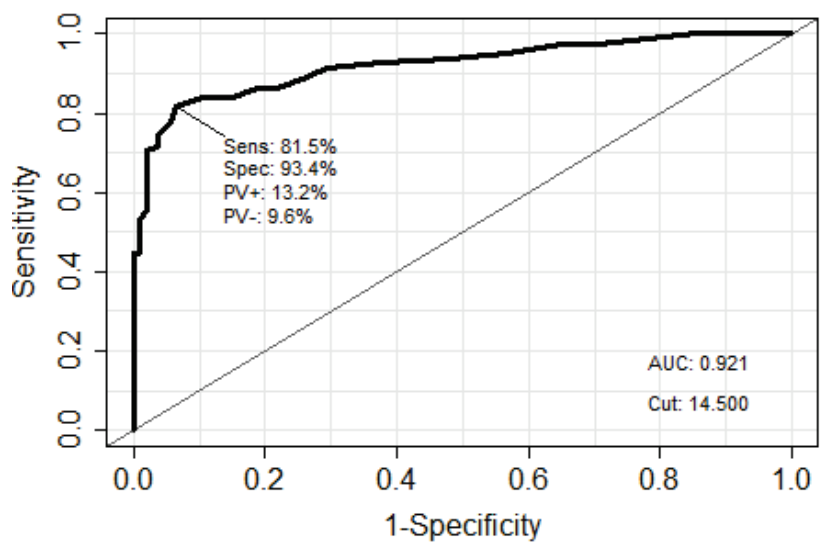

B)

ROC curve: BMI

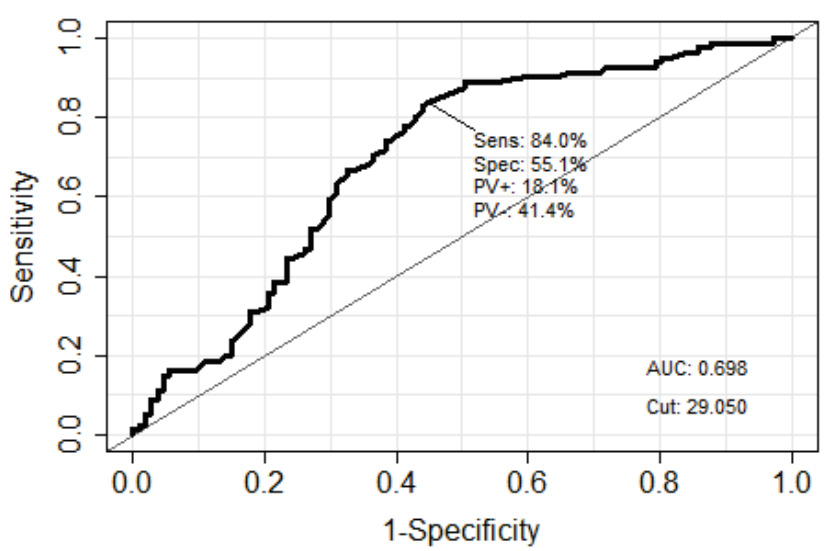

D)

ROC curve: $t 90$

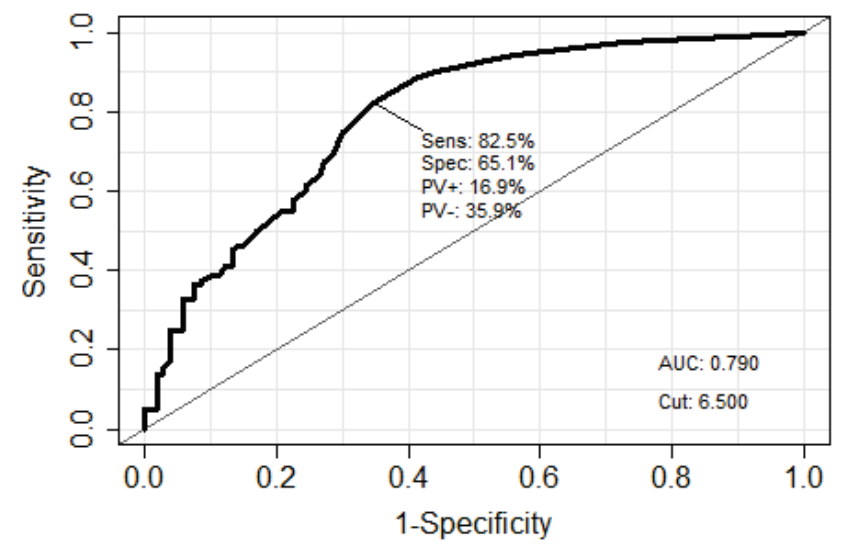

F)

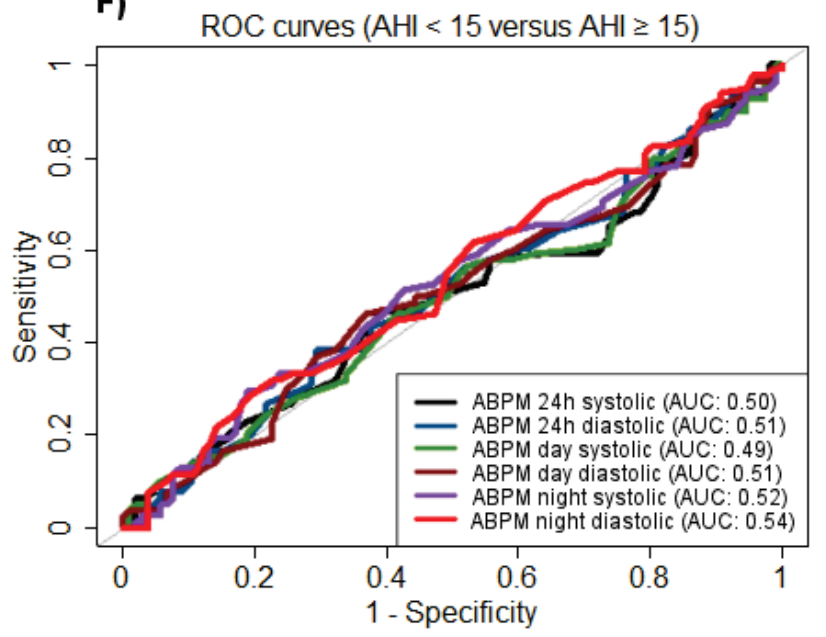

Fig. 4. ROC curves with $A U C$ values for subgroups of patients with $A H I=0-14.9$ (non-SA, mild $S A$ ) and $A H I \geq 15$ (moderate and severe $\mathrm{SA}$ ) in patient subgroups according to the $\mathbf{A}$ ) age, B) BMI, C) mean night $\mathrm{SpO}_{2}$, D) t90, E) ODI, G) ABPM parameters. 


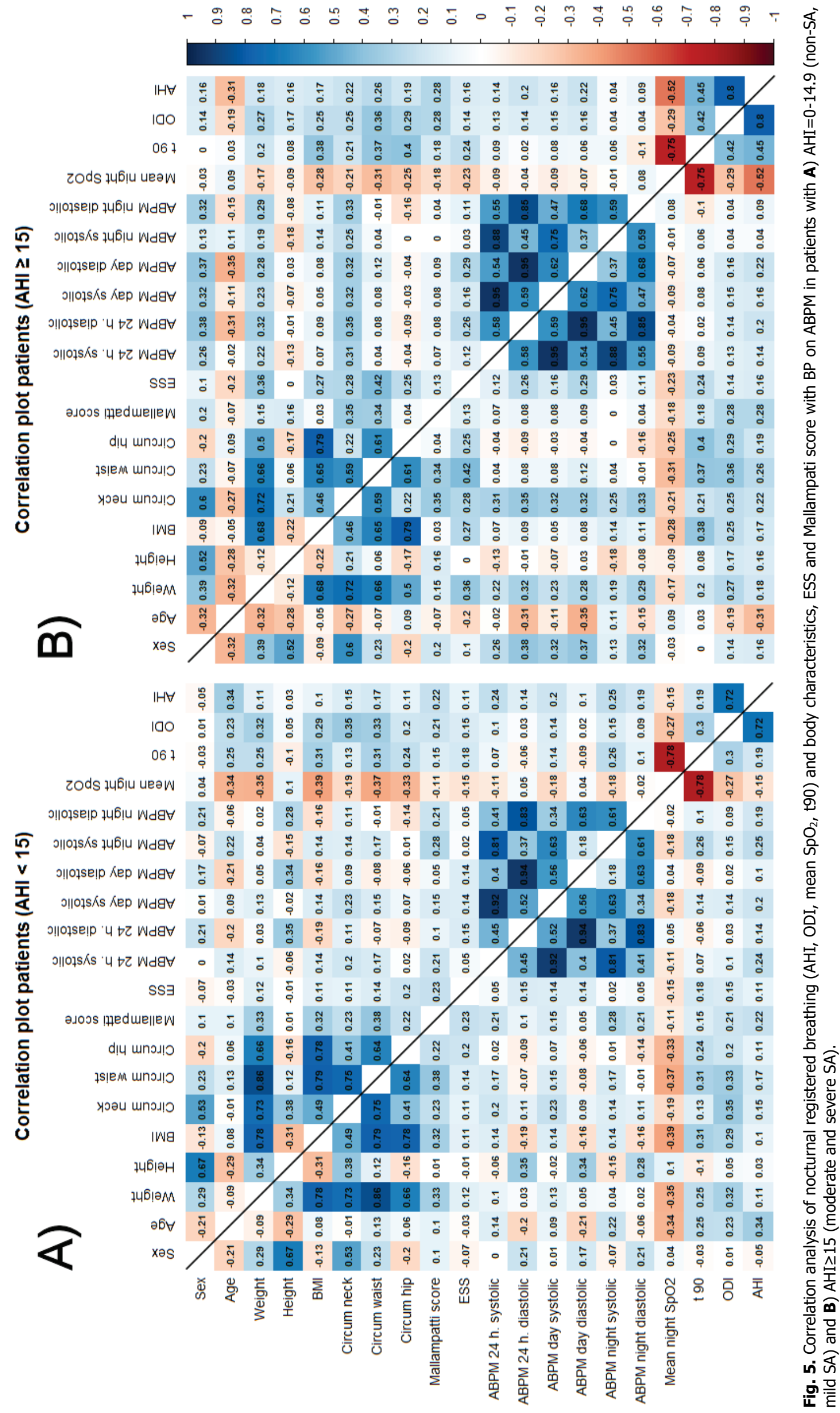




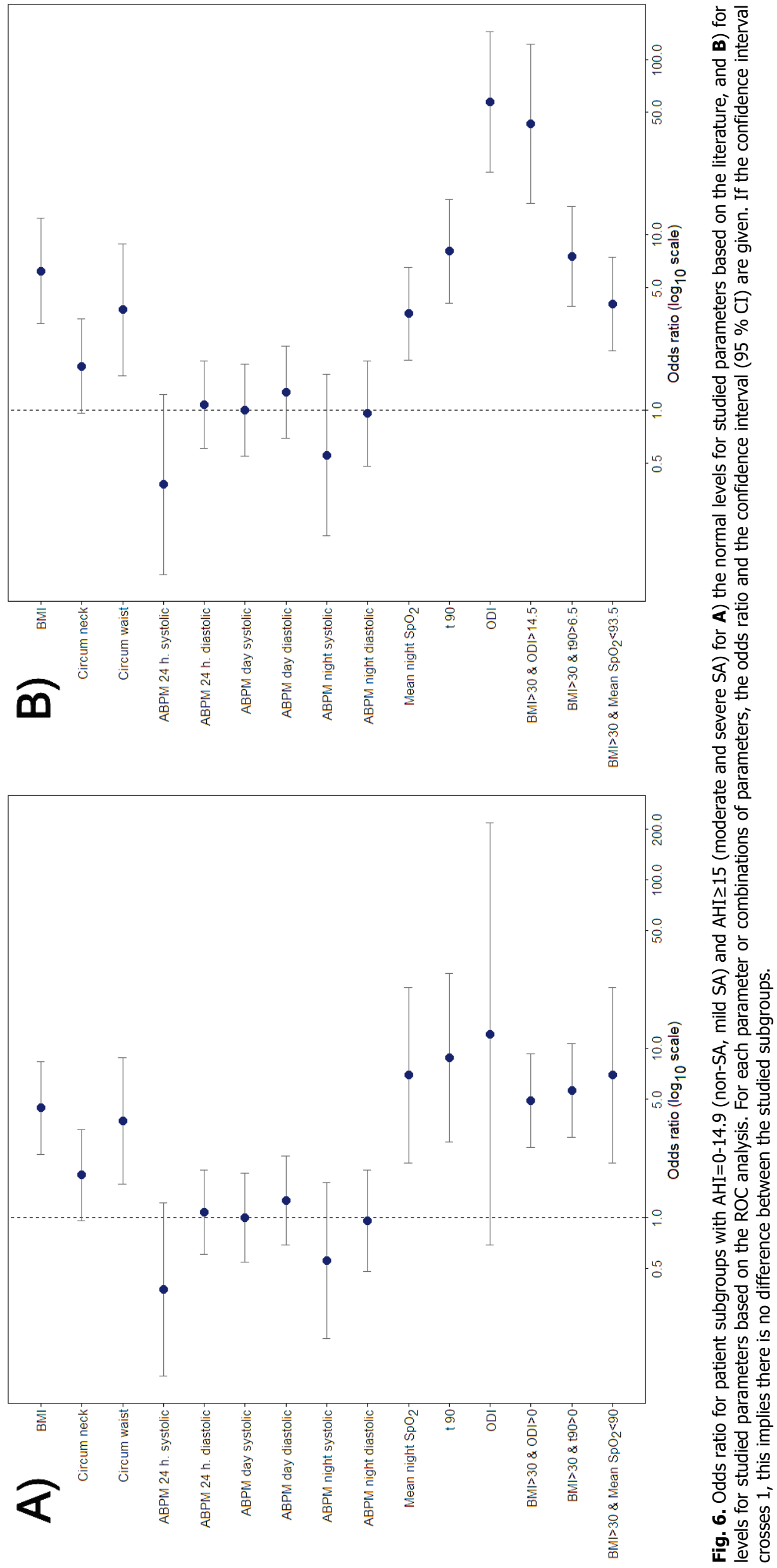


Comparison of parameters associated with moderate and severe $S A$

The odds ratios were used to determine whether studied parameters are associated with moderate or severe SA as assessed by AHI, and to compare the magnitude of various risk factors for that outcome (AHI=0-14.9 vs. $\mathrm{AHI} \geq 15$ ).

Figure 6 shows the results of a logistic regression model used to explore the relationship between clinical and laboratory data and the occurrence of moderate and severe $\mathrm{SA}$, defined as $\mathrm{AHI} \geq 15$. Sleep respiration characteristics such as 190 (odds ratio $=8.82$, $95 \% \mathrm{CI}=2.80$ to 27.87), mean night $\mathrm{SpO}_{2}$ (6.96, 2.10-23.10), and ODI (12.16, 0.68-216.17) were associated with having an increased likelihood of moderate/severe SA (Fig. 6A). Additional characteristics associated with an increased likelihood of moderate/severe SA were BMI (4.44, 2.37-8.36), neck circumference (1.78, 0.96-3.31) and waist circumference $(3.73,1.57-8.83)$. No correlations of AHI were observed for any of ABPM parameters: 24-h systolic (0.37, 0.12-1.22), 24-h diastolic (1.07, 0.60-1.90), daytime $(1.00,0.54-1.82)$, daytime diastolic (1.26, $0.69-2.31)$, nighttime systolic $(0.55,0.19-1.60)$, nighttime diastolic $(0.95,0.47-1.90)$. The confidence interval crosses 1 for all APBM parameters. This implies there is no association between the studied APBM parameters and $\mathrm{AHI}$.

When the analysis was performed for cut-off values revealed from ROC curves, ODI higher 14.5 markedly increased the likelihood of moderate/severe SA (57.49, 22.79-145.01) (Fig. 6B). The increased likelihood of moderate/severe SA was associated with higher 190 (cut-off 8.07, 4.09-15.92), mean night $\mathrm{SpO}_{2}$ (3.55, 1.92-6.59), BMI (6.22, 3.10-12.49), neck circumference (1.78, 0.96-3.31), waist circumference $(3.73,1.57-8.83)$, but not with any of the ABPM parameters (Fig. 6B).

Moreover, we did not reveal an additional significant effect on likelihood of moderate/severe SA when we combined any respiratory parameter (t90, ODI, mean night $\mathrm{SpO}_{2}$ ) with BMI (Fig. 6).

Comparison of patients with isolated nocturnal hypertension vs. both daytime-nighttime hypertensions

In order to determine whether patients with nocturnal hypertension and daytime normotensive BP have a higher incidence of SA than those with daytime and nighttime hypertensions, we compared respiratory parameters, anthropometric and anamnestic data between these patient subgroups. There was no statistically significant difference in respiratory parameters for the group with nocturnal hypertension and daily normotension $(\mathrm{n}=44)$ compared with daytime and nighttime hypertensives $(\mathrm{n}=144)$ : AHI $(\mathrm{p}=0.297)$, ODI $(\mathrm{p}=0.914)$, mean night saturation $(\mathrm{p}=0.104), \mathrm{t} 90$ $(p=0.081)$, ESS $(p=0.089)$. We observed higher body weight $(\mathrm{p}=0.048)$ and larger neck circumference $(\mathrm{p}=0.031)$ in the subgroup of patients with nighttime hypertension and normotension in the day. There was no difference either in age $(\mathrm{p}=0.141)$, waist $(\mathrm{p}=0.519)$, and hip $(p=0.374)$ between the subgroups of patients with isolated nocturnal hypertension and normotension in the day.

\section{Discussion}

This prospective multicenter study showed a high prevalence of SA (72.9\%) in patients with nocturnal hypertension diagnosed by ABPM.

Our results from the Czech patient cohort indicate that SA does not bother patients with nocturnal hypertension, even though $20.2 \%$ reported increased daytime sleepiness $(E S S \geq 10)$. Previous studies indicate that $30 \%$ of hypertensive patients have OSA and conversely $50 \%$ of patients with OSA have hypertension (Peppard et al. 2000). Our results on nocturnal hypertension are consistent with studies of resistant hypertension (Logan et al. 2001, Gonçalves et al. 2007, Pedrosa et al. 2011). Hypertension in patients with OSA often presents during the night and has the form of a non-dipper type (Baquet et al. 2009). There was a high percentage of non-dippers in our group. This non-dipping pattern can be explained by the increased adrenergic activity during the night in SA as a result of apnoic pause and intermittent hypoxia. There may be also other factors involved as shown e.g. for melatonin reducing BP in rats due inhibition of sympathetic nerve activity (Klimentova et al. 2016). Even a mild OSA may prevent nocturnal physiological decrease in BP and can even increase it (Wolf et al. 2010). Sekizuka et al. (2010) showed that OSA causes nocturnal BP rise even in OSA patients without hypertension. Treating OSA with CPAP leads to a significant decrease in BP (Montesi et al. 2012).

Several studies showed that ABPM correlates more closely with organ damage and morbid or fatal events than office BP (Mancia et al. 2013). According to the American Heart Association, SA is considered one of the most common identifiable causes of hypertension (Calhoun et al. 2008). Previously published studies found 
a linear relationship between ABPM and AHI (Young et al. 1997) and correlation of BP during sleep with AHI (Lavie et al. 1993). Recent epidemiological studies have yielded conflicting data on whether patients with OSA are at increased risk of developing hypertension or whether the frequent development of hypertension is due to other associated factors, such as age, BMI, neck circumference, alcohol and smoking (Cano-Pumarega et al. 2011, Marin et al. 2012). In our study, there was no correlation of AHI with ABPM in any measurement. Similarly Lévy et al. (2011) found no correlation between AHI and nocturnal hypertension. Here, the question is whether OSA is not only a confounding factor in hypertension caused by metabolic parameters, which could support previous epidemiologic studies (CanoPumarega et al. 2011, Marin et al. 2012). In our patients with nighttime hypertension and normotension during the day, we observed association with higher body weight and larger neck circumference.

Despite no association of AHI with ABPM in any measurement, we observed strong association of moderate and severe SA with body characteristics, particularly with BMI and waist circumference, and oxygenation parameters. A likehood of moderate and severe SA was markedly enhanced by ODI $>14.5 \%$, t $90>6.5 \%$ and mean night $\mathrm{SpO}_{2}<93.5 \%$, followed by body characteristics such as BMI $>29.05 \mathrm{~kg} / \mathrm{cm}^{2}$ and waist circumference $>105.5 \mathrm{~cm}$. Nevertheless, the decrease of oxygenation parameter may be not only a sign of SA, but of nocturnal hypoventilation in obesity patients thus further supporting the key role of anthropometric parameters in these patients. Importantly, we did not observe any association of severity of SA with any of ABPM parameters. A multivariate analysis did not confirm that combination of BMI or their body characteristics with any oxygenation parameters enhance the likelihood of moderate and severe SA.

In ABPM there were more patients with normal diastolic pressure. In elderly patients this was lower due to frequent isolated systolic hypertension. A number of patients in our sample met the criteria for a diagnosis of resistant hypertension (i.e. patients taking at least three medications, one of which was a diuretic) (Mancia et al. 2013). Our data are in line with the literature on the high incidence of OSA in drug resistant hypertension (Logan et al. 2001, Gonçalves et al. 2007, Pedrosa et al. 2011). OSA is currently recognized as an independent risk factor for cardiovascular diseases (CHD, hypertension, cardiac arrhythmias and stroke) (McNicholas and Bonsigore
2007, Bradley and Floras 2009, Pedrosa et al. 2011, Jaffe et al. 2013). In our group of patients with proven SA, the medical records revealed a fourfold higher incidence of CHD, and more than twice as frequent myocardial infarction than in patients without SA.

Despite high prevalence of SA (72.9\%) in patients with nocturnal hypertension, subgroups with nocturnal hypertension had no higher incidence of SA compared to those who had night and day hypertension. In this exploratory study, we did not analyze other phenotypes and subgroups according to comorbidity, thus future investigation in larger sample cohorts are needed.

To evaluate symptoms of OSA, we used the ESS (subjective daytime sleepiness). The ESS did not prove to be a good screening test: in the whole group, the mean ESS was within the norm (6.3), and even though in patients with confirmed SA there was a higher proportion with $\mathrm{ESS} \geq 10$, the difference between groups was not statistically significant. Our results are consistent with similar recent work showing that the ESS is not an adequate screening tool for OSA in patients with night or resistant hypertension (Abrishami et al. 2010, Parati et al. 2013).

Suspected SA in routine clinical examination can often be demonstrated by Mallampati class. In line with the literature (Nuckton et al. 2006), our patients with SA often demonstrated impaired visibility pharyngeal area due to the decline of soft palate and pharyngeal narrowing. There are also other published data (Hukins 2010), where Mallampati class was associated with AHI but did not modify likelihood of severe SA or absence of SA. Our study showed a significant difference in incidence of the most reduced visibility of oropharyngx, Mallampati class IV, between groups with and without evidence of SA. However, no Mallampati class relationship to $\mathrm{BP}$ on $\mathrm{ABPM}$ was proven. According to our knowledge, this is the first report on Mallampati class in hypertensive patients.

This study has several limitations. The patients were recruited from routine examinations from local cardiologists and internists, and there is no information regarding the number of patients who were screened for the presence of nocturnal hypertension and the percentage of patients who had nocturnal hypertension. Moreover, we do not know the primary reason for the investigation of patients by the cardiologists and internists.

\section{Conclusions}

Our data demonstrated that SA is frequently 
associated with nocturnal and pharmacoresistant hypertension and is underdiagnosed in patients with nocturnal hypertension. SA severity was associated with body characteristics and oxygenation parameters, but not with ABMP parameters and Mallampati score. Thus, especially obese patients with nocturnal hypertension and a non-dipping night BP pattern, breathing during sleep should be investigated for presence of SA.

\section{Conflict of Interest}

There is no conflict of interest.

\section{Acknowledgements}

Supported by RVO: 61989592, MH CZ - DRO (FNOl, 00098892) and ČARO (Czech Alliance against Chronic
Respiratory Diseases).

\section{Abbreviations}

ABPM - ambulatory blood pressure monitoring, AHI - apnoea-hypopnoea index, AUC - area under curve, BMI - body mass index, BP - blood pressure, CHD - coronary heart disease, CPAP - continuous positive airway pressure, ESS - Epworth sleepiness scale, Mean $\mathrm{SpO}_{2}$ - mean night saturation (\%), $\mathrm{NH}$ - nocturnal hypertension, ODI - oxygen desaturation index, OSA obstructive sleep apnoea, ROC - Receiver-Operator Characteristic curves, $\mathrm{SA}$ - sleep apnoea, $\mathrm{SaO}_{2}$ - oxygen saturation, SDB - sleep-disordered breathing, t90 - time in saturation below $90 \% \mathrm{SaO}_{2}$, expressed in $\%$.

\section{References}

ABRISHAMI A, KHAJEHDEHI A, CHUNG F: A systematic review of screening questionnaires for obstructive sleep apnea. Can J Anaesth 57: 423-438, 2010.

BAQUET JP, BARONE-ROCHETTE G, PÉPIN JL: Hypertension and obstructive sleep apnoea syndrome: current perspectives. J Hum Hypertension 23: 431-443, 2009.

BRADLEY TG, FLORAS JS: Obstructive sleep apnoea and its cardiovascular consequences. Lancet 373: 82-93, 2009.

CALHOUN DA, JONES D, TEXTOR S, GOFF DC, MURPHY TP, TOTO RD, WHITE A, CUSHMAN WC, WHITE W, SICA D, FERDINAND K, GILES TD, FALKNER B, CAREY RM: Resistant hypertension: diagnosis, evaluation, and treatment: a scientific statement from the American Heart Association Professional Education Committee of the Council for High Blood Pressure Research. Hypertension 51: 1403-1419, 2008.

CANO-PUMAREGA I, DURÁN-CANTOLLA J, AIZPURU F, MIRANDA-SERRANO E, RUBIO R, MARTÍNEZNULL C, DE MIGUEL J, EGEA C, CANCELO L, ALVAREZ A, FERNÁNDEZ-BOLAÑOS M, BARBÉ F: Obstructive sleep apnea and systemic hypertension: longitudinal study in the general population: the Vitoria Sleep Cohort. Am J Respir Crit Care Med 184: 1299-1304, 2011.

ERMAN MK, STEWART D, EINHORN D, GORDON N, CASAL E: Validation of the ApneaLink for the screening of sleep apnea: a novel and simple single-channel recording device. J Clin Sleep Med 3: 387-392, 2007.

FERNANDEZ-MENDOZA J, VGONTZAS AN, LIAO D, SHAFFER ML, VELA-BUENO A, BASTA M, BIXLER EO: Insomnia with objective short sleep duration and incident hypertension: the Penn State Cohort. Hypertension 60: 929-935, 2012.

FLEMONS WW, BUYSSE D, REDLINE S, PACK A, STROHL K, WHEATLEY J, YOUNG T, DOUGLAS N, LEVY P, MCNICHOLAS W, FLEETHAM J, WHITE D, SCHMIDT-NOWARRA W, CARLEY D, ROMANIUK J: Sleep-related breathing disorders in adults: recommendations for syndrome definition and measurement techniques in clinical research. The Report of an American Academy of Sleep Medicine Task Force. Sleep 22: 667-689, 1999.

GONÇALVES SC, MARTINEZ D, GUS M, DE ABREU-SILVA EO, BERTOLUCI C, DUTRA I, BRANCHI T, MOREIRA LB, FUCHS SC, DE OLIVEIRA AC, FUCHS FD: Obstructive sleep apnea and resistant hypertension: a case-control study. Chest 132: 1858-1862, 2007.

HUKINS C: Mallampati class is not useful in the clinical assessment of sleep clinic patients. J Clin Sleep Med 6: 545-549, 2010.

JAFFE LM, KJEKSHUS J, GOTTLIEB SS: Importance and management of chronic sleep apnoea in cardiology. Eur Heart J 34: 809-815, 2013.

JOHNS MW: A new method for measuring daytime sleepiness: the Epworth sleepiness scale. Sleep 14: 540-545, 1991. 
KHAN A, PATEL NK, O'HEARN DJ, KHAN S: Resistant hypertension and obstructive sleep apnea. Int J Hypertens 2013: 193010, 2013.

KLIMENTOVA J, CEBOVA M, BARTA A, MATUSKOVA Z, VRANKOVA S, REHAKOVA R, KOVACSOVA M, PECHANOVA O: Effect of melatonin on blood pressure and nitric oxide generation in rats with metabolic syndrome. Physiol Res 65 (Suppl 3): S373-S380, 2016.

KONECNY T, KARA T, SOMERS VK: Obstructive sleep apnea and hypertension: an update. Hypertension 63: 203-209, 2014.

LAVIE P, YOFFE N, BERGER I, PELED R: The relationship between the severity of sleep apnea syndrome and 24-h blood pressure values in patients with obstructive sleep apnea. Chest 103: 717-721, 1993.

LÉVY P, TAMISIER R, MINVILLE C, LAUNOIS S, PÉPIN JL: Sleep apnoea syndrome in 2011: current concepts and future directions. Eur Respir Rev 20: 134-146, 2011.

LINDBERG E: Epidemiology of OSA. In: Sleep Apnea. MCNICHOLAS WT, BONSIGNORE MR (eds), Eur Respir Mon 50, Plymouth: European Respiratory Society, 2010, pp 51-68.

LOGAN AG, PERLIKOWSKI SM, MENTE A, TISLER A, TKACOVA R, NIROUMAND M, LEUNG RS, BRADLEY TD: High prevalence of unrecognized sleep apnoea in drug-resistant hypertension. J Hypertens 19: 2271-2277, 2001.

MALLAMPATI SR: Clinical sign to predict diffucult tracheal intubation (hypothesis). Can Anaesth Soc J 30: 316-317, 1983.

MANCIA G, FAGARD R, NARKIEWICZ K, REDON J, ZANCHETTI A, BÖHM M, CHRISTIAENS T, CIFKOVA R, DE BACKER G, DOMINICZAK A, GALDERISI M, GROBBEE DE, JAARSMA T, KIRCHHOF P, KJELDSEN SE, LAURENT S, MANOLIS AJ, NILSSON PM, RUILOPE LM, SCHMIEDER RE, SIRNES PA, SLEIGHT P, VIIGIMAA M, WAEBER B, ZANNAD F: 2013 ESH/ESC Guidelines for the management of arterial hypertension: the Task Force for the management of arterial hypertension of the European Society of Hypertension (ESH) and of the European Society of Cardiology (ESC). J Hypertens 31: 1281-1357, 2013.

MARIN JM, AGUSTI A, VILLAR I, FORNER M, NIETO D, CARRIZO SJ, BARBÉ F, VICENTE E, WEI Y, NIETO FJ, JELIC S: Association between treated and untreated obstructive sleep apnea and risk of hypertension. JAMA 307: 2169-2176, 2012.

MCNICHOLAS WT, BONSIGORE MR: Sleep apnoea as an independent risk factor for cardiovascular disease: current evidence, basic mechanisms and research priorities. Eur Respir J 29: 156-178, 2007.

MONTESI SB, EDWARDS BA, MALHOTRA A, BAKKER JP: The effect of continuous positive airway pressure treatment on blood pressure: a systematic review and meta-analysis of randomized controlled trials. $J$ Clin Sleep Med 8: 587-596, 2012.

NUCKTON TJ, GLIDDEN DV, BROWNER WS, CLAMAN DM: Physical examination: Mallampati score as an independent predictor of obstructive sleep apnea. Sleep 29: 903-908, 2006.

PARATI G, LOMBARDI C, HEDNER J, BONSIGNORE MR, GROTE L, TKACOVA R, LEVY P, RIHA R, BASSETTI C, NARKIEWICZ K, MANCIA G, MCNICHOLAS WT: Position paper on the management of patients with obstructive sleep apnea and hypertension: joint recommendations by the European Society of Hypertension, by the European Respiratory Society and by the members of European COST (Cooperation in Scientific and Technological research) ACTION B26 on obstructive sleep apnea. J Hypertens 30: 633-646, 2012.

PARATI G, LOMBARDI C, HEDNER J, BONSIGNORE MR, GROTE L, TKACOVA R, LÉVY P, RIHA R, BASSETTI C, NARKIEWICZ K, MANCIA G, MCNICHOLAS WT: Recommendations for the management of patients with obstructive sleep apnoea and hypertension. Eur Respir J 41: 523-538, 2013.

PARATI G, STERGIOU G, O'BRIEN E, ASMAR R, BEILIN L, BILO G, CLEMENT D, DE LA SIERRA A, DE LEEUW P, DOLAN E, FAGARD R, GRAVES J, HEAD GA, IMAI Y, KARIO K, LURBE E, MALLION JM, MANCIA G, MENGDEN T, MYERS M, OGEDEGBE G, OHKUBO T, OMBONI S, PALATINI P, REDON J, RUILOPE LM, SHENNAN A, STAESSEN JA, VANMONTFRANS G, VERDECCHIA P, WAEBER B, WANG J, ZANCHETTI A, ZHANG Y: European Society of Hypertension practice guidelines for ambulatory blood pressure monitoring. J Hypertens 32: 1359-1366, 2014. 
PEDROSA RP, DRAGER LF, GONZAGA CC, SOUSA MG, DE PAULA LKG, AMARO AC, AMODEO C, BORTOLOTTO LA, KRIEGER EM, BRADLEY TD, LORENZI-FILHO G: Obstructive sleep apnea: the most common secondary cause of hypertension associated with resistant hypertension. Hypertension 58: 811-817, 2011.

PEPPARD PE, YOUNG T, PALTA M, SKATRUD J: Prospective study of the association between sleep-disordered breathing and hypertension. N Engl J Med 342: 1378-1384, 2000.

PHILLIPS CL, O’DRISCOLL DM: Hypertension and obstructive sleep apnea. Nat Sci Sleep 5: 43-52, 2013.

QASEEM A, DALLAS P, OWENS DK, STARKEY M, HOLTY JE, SHEKELLE P: Diagnosis of obstructive sleep apnea in adults: a clinical practice guideline from the American College of Physicians. Ann Intern Med 161: 210-220, 2014.

SEKIZUKA H, KIDA K, AKASHI YJ, YONEYAMA K, OSADA N, OMIYA K, MIYAKE F: Relationship between sleep apnea syndrome and sleep blood pressure in patients without hypertension. J Cardiol 55: 92-98, 2010.

TORRES G, SÁNCHEZ-DE-LA-TORRE M, BARBÉ F: Relationship between OSA and hypertension. Chest 148: 824-832, 2015.

WOLF J, HERING D, NARKIEWICZ K: Non-dipping pattern of hypertension and obstructive sleep apnea syndrome. Hypertens Res 33: 867-871, 2010.

YOUNG T, PEPPARD P, PALTA M, HLA KM, FINN L, MORGAN B, SKATRUD J: Population-based study of sleep-disordered breathing as a risk factor for hypertension. Arch Intern Med 157: 1746-1752, 1997. 